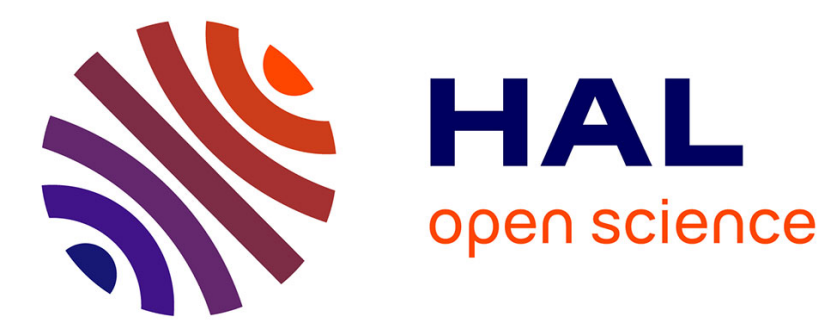

\title{
Predicting explosibility properties of chemicals from quantitative structure-property relationships
}

Guillaume Fayet, Patricia Rotureau, Laurent Joubert, Carlo Adamo

\section{To cite this version:}

Guillaume Fayet, Patricia Rotureau, Laurent Joubert, Carlo Adamo. Predicting explosibility properties of chemicals from quantitative structure-property relationships. Process Safety Progress, 2010, 29 (4), pp.359-371. 10.1002/prs.10379 . ineris-00961753

HAL Id: ineris-00961753

https://hal-ineris.archives-ouvertes.fr/ineris-00961753

Submitted on 20 Mar 2014

HAL is a multi-disciplinary open access archive for the deposit and dissemination of scientific research documents, whether they are published or not. The documents may come from teaching and research institutions in France or abroad, or from public or private research centers.
L'archive ouverte pluridisciplinaire HAL, est destinée au dépôt et à la diffusion de documents scientifiques de niveau recherche, publiés ou non, émanant des établissements d'enseignement et de recherche français ou étrangers, des laboratoires publics ou privés. 


\title{
PREDICTING EXPLOSIBILITY PROPERTIES OF CHEMICALS FROM QUANTITATIVE STRUCTURE-PROPERTY RELATIONSHIPS
}

\author{
G. Fayet ${ }^{1,2}$, P. Rotureau ${ }^{2 *}$, L. Joubert ${ }^{1}$ and C. Adamo ${ }^{1}$
}

${ }^{1}$ Laboratoire d'Electrochimie, Chimie des Interfaces et Modélisation pour l'Energie, CNRS UMR-7575, Ecole Nationale Supérieure de Chimie de Paris, 11 Rue P. et M. Curie, 75231 Paris Cedex 05, France

${ }^{2}$ Institut National de l'Environnement Industriel et des Risques (INERIS), Parc Technologique Alata, BP2, 60550 Verneuil-en-Halatte, France

* Corresponding author. Tel.: +33(3) 445563 29. Fax: +33(3) 44556565.

E-mail address: patricia.rotureau@ineris.fr 


\begin{abstract}
Quantitative Structure-Property Relationship (QSPR) type methods have been up to now mainly devoted to biological, toxicological applications but their use to predict physicochemical properties is a growing interest. In this context, an original approach associating QSPR methods and quantum chemical calculations for the prediction of chemicals explosibility properties is presented here.

Indeed, the new European regulation of chemicals named REACH implies the new assessment of a tremendous number of substances for their hazardous properties. But, the complete characterization of toxicological, ecotoxicological and physico-chemical hazards at experimental level is incompatible with the imposed calendar of REACH. Hence, there is a real need in evaluating capabilities of alternative methods for assessing hazardous properties as a screening process.

This contribution focuses on models that have been established to predict accurately the thermal stability and electric spark sensitivity of a series of potentially explosive nitroaromatic molecules. Descriptors related to their molecular structure (topological, geometrical, electronic, quantum chemical), partially obtained from Density Functional Theory (DFT) calculations, were computed and statistical analyses (multilinear regressions) were performed to link the adequate molecular descriptors with the experimental properties. These first results coupling theoretical calculations and QSPR methods open new perspectives for the prediction of other physico-chemical properties.
\end{abstract}

\title{
Introduction
}

Within the context of the new European regulatory framework for the "Registration, Evaluation and Authorization of Chemicals" (REACH) [1] and its related Globally Harmonized System (GHS) for classification and labeling of chemical products [2], evaluation of properties based on predictive methods (computer-assisted chemical risk assessment or molecular modeling methods) are greatly encouraged. Indeed, all manufacturers, importers and suppliers of chemicals must identify and manage risks linked to the substances they manufacture and market (in quantity greater than 1 tonn). It means that thousands of substances are under concern and have to be tested not only for their toxicological and environmental impact but also for their physico-chemical properties. Taking into account the above considerations, there is a real need for the development of alternative predictive tools to reduce unnecessary animal tests but also time-consuming, costly and potentially hazardous tests. As a minimum requirement of REACH, the potential effects to human health shall be assessed for the following physico-chemical properties: explosivity, flammability and oxidizing potential. In particular, the characterization of explosive property of molecules in terms of performance and sensitivity is quite complex and based on a series of tests aiming to evaluate detonation or deflagration behavior on one hand and the ability of compounds to release energy under various stimuli (heat, impact, shock, electric spark) on the other hand. In regulatory chemical frameworks (GHS or transport of dangerous goods for example), preliminary screening procedures and chemical knowledge are used prior to experience to estimate chemicals which may have explosive properties with a minimum of information. This consists of examining first the structure of the molecules and particularly the presence of well known "explosophore" groups (such as the nitro group) and to calculate the oxygen balance (OB). Then, the thermal stability of the substance is considered and can be generally evaluated by calorimetric methods. Indeed, according to the UN Manual of Test and criteria [3] (which is used in REACH) and to the GHS, further testing is not 
required if the exothermic decomposition energy is less than $500 \mathrm{~J} / \mathrm{g}$ and the onset of exothermic decomposition is below $500{ }^{\circ} \mathrm{C}$.

Some computational works and tools based on thermodynamic concepts already exist to estimate reactivity and chemical explosive hazards. For example, the American Society for Testing Materials (ASTM) proposed the CHETAH (Chemical Engineering Thermodynamics and Hazard Evaluation) software [4] which provides thermodynamic data (heat of formation, combustion...), estimated by means of the Benson group contribution method [5]. To evaluate these chemical hazards, CHETAH uses also empirical criteria like the oxygen balance developed in the 1940's by Lothrop et al. [6]. Although user friendly and computationally inexpensive, this program can fail when Benson group values are missing or erroneous and do not take into account sensitivities of substances to the different initiation modes. Another approach is the Calculated Adiabatic Reaction Temperature (CART) [7] based on calculated activation energies. Nevertheless, these two methods are generally considered for more qualitative than quantitative uses through a hazard classification according to threshold values of their particular criteria [8].

The tool in development in the present project is based on a slightly different philosophy considering the explosives properties (in particular those considered in chemicals regulations, which include initiation sensitivities) through quantitative structure-property relationships (QSPR) models applicable for different classes of explosive substances (nitroalkanes, nitric esters, nitramines, aromatic nitrated derivatives...). This last methodology is already widely used in toxicology $[9,10]$, biology $[11,12]$ or drug design $[13,14]$ and is in growing interest for predicting physico-chemical properties [15-17]. It consists in developing predictive models between the molecular structures and a macroscopic measurable property of substances. The final goal of our project is to integrate such predictive models, validated for the different explosive properties and classes of explosives, under a unique interface. From an input chemical structure, the different physico-chemical data will be calculated. Then the tool will help users to determine if further experimental investigations are needed to evaluate explosive hazards of potentially explosive substances. Of course, depending upon the structure and complexity of the developed QSPR models and descriptors, the different modules of the tool (input, descriptors calculations, output) will have to be adapted. For instance, depending of whether $3 \mathrm{D}$ structures or simple elemental compositions are needed, the way to input structures in the tool will be different. Graphically, an interface similar to the one used by the PubChem platform [18,19], which provides information on biological activities, could be built. Finally, such a screening tool will complement the existing experimental evaluation, in particular in the actual regulatory context concerning the management of chemicals.

The first step in the development of this screening tool is dedicated to the development of QSPR models for a specific class among explosive substances which are nitroaromatic compounds. These compounds are considered with particular attention among energetic materials as their decomposition process is complex with different possible reaction paths [20,21]. In particular, molecules substituted in ortho position with the nitro group present specific decomposition channels [22]. Some eligible properties included in the management of potentially explosive substances have already been widely investigated. For instance, Keshavarz [23-26], Kamlet [27,28] and Rice [29,30] developed predictive models for the impact sensitivity of various classes of molecules. Our investigations have been focused on two less studied properties. The first one is the decomposition enthalpy taken as an indicator of thermal stability estimated in preliminary screening procedures before performing tests. The second one is the electric spark or electrostatic sensitivity which is not 
required in regulatory contexts concerning chemicals but remains in practice very important to consider all kinds of sensitivities of energetic compounds. We assume that these properties are less studied because only few large and reliable databases are available in the literature. The originality of the present work consists in the use of quantum chemical calculations (in particular the density functional theory) which allow to introduce chemical comprehensive descriptors in the developed predictive models to better understand explosion mechanisms.

\section{Methods}

\section{QSPR methodology}

The quantitative structure-property relationship (QSPR) methodology is, as illustrated in figure 1, based on the development of a mathematical relation between a macroscopic property and the molecular structure for a particular set of similar compounds.

Molecular scale properties, most of the time calculated, are used as descriptors of the chemical structure while the property values are provided from an experimental data set. Then, different approaches are used to set up the model: artificial neural networks [31], genetic algorithms [32] or statistical analyses such as multilinear regressions.

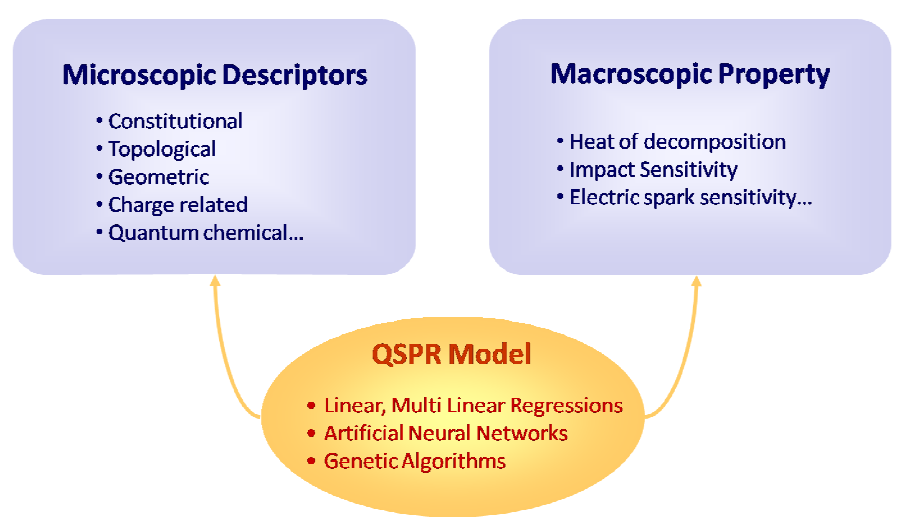

Figure 1. QSPR principle dedicated to the prediction of explosive properties.

If the computational parameters are very important for such an approach, the main limit for building up such chemical QSPR models remains the reliability of the experimental training data set. This is particularly important for the kind of properties under interest in this project. Only few experimental data are on disposal and they are sensitive to experimental conditions and protocols. Furthermore, to develop a valid and reliable QSPR model, this data set must present a homogeneous and representative distribution. This data set is ideally divided into two parts: a training set used to build the model and a validation set to estimate the predictivity of the obtained model. In this study, only few experimental data are available. So, a unique set has been used, models reliability being estimated from the cross-validation technique [33].

\section{Molecular Descriptors}


A tremendous number of descriptors can be considered [33] to characterize the structures of molecules. For the compounds considered in this paper, up to 300 molecular descriptors have been calculated using CodessaPro software [34]. Different kinds of descriptors can be exhibited:

- constitutional: number of specific atoms, functional group, bonds;

- topological: atomic connectivity in the molecule giving information about size, composition and branching degree;

- geometric: distances, angles, molecular volume;

- charge related descriptors: distribution of charge in the molecule (partial atomic charges...);

- thermodynamic: heat capacity, energies and their different contributions (vibrational, rotational, translational);

- quantum chemical: binding information, molecular orbital energies, reactivity indices.

Other descriptors like the oxygen balance or reactivity indices arising from DFT calculations (e.g. bond dissociation energy) have been calculated. Details of the descriptors used are available on request.

\section{Computational details}

All descriptors have been computed from quantum chemical calculated structures, i.e. structures have been firstly calculated using quantum chemical software and then loaded into CodessaPro software.

Two quantum chemical approaches have been used: the density functional theory (DFT) and a semi-empirical one. The main difference between these two approaches is that DFT methods are based on the assumption that electron density is sufficient to characterize systems whereas semiempirical ones introduce approximations (based on empirical considerations) in the Hartree-Fock (HF) equations. Whereas semi-empirical methods consume less computer times, DFT methods include less (empirical) approximations ensuring better reliability in calculations. In practice, DFT methods are commonly considered as a good compromise between computer times and reliability.

In this paper, DFT calculations were performed with the parameter-free PBE0 hybrid functional [35] and a 6-31+G(d,p) basis set by using Gaussian 03 [36] and the semi-empirical AM1 (Austin Method 1) [37] as implemented in Hyperchem 7.0 [38]. The pertinence of the DFT level has been checked for such systems in ref [20,22]. AM1 is the most popular semi-empirical level for this kind of studies [39-42]. Structure optimization and harmonic frequency calculations have been performed at both levels and all structures have been checked to present no imaginary frequency, ensuring that all stationary points are stable species.

\section{Statistical analysis and evaluation of models}

All statistical analyses were computed using CodessaPro software [34,43]. The calculated multi linear regressions have the following form.

$$
Y=a_{0}+\sum_{i} a_{i} X_{i}
$$

where $Y$ is the property to predict, $X_{i}$ are the molecular descriptors and $a_{i}$ the corresponding regression constants. 
The Best Multi Linear Regression (BMLR) procedure was used to obtain the most predictive models. This method consists in considering the most correlated pairs of orthogonal (i.e. not intercorrelated) descriptors and adding successively other orthogonal descriptors to give the best correlated model at higher ranks (i.e. using more descriptors). The final model is chosen as the equation providing the best correlation with experimental data and preventing, at the same time, against any over-parameterization.

The reliability of the models were estimated through several parameters, such as the resulting coefficients $\mathrm{R}^{2}$ and the corrected $\mathrm{R}^{2}{ }_{\mathrm{cv}}$ (using the cross-validation technique [34]). The significance of each descriptor in the equations was validated by performing a Student $t$-test validation at a $95 \%$ confidence level.

Once a reliable model is obtained, it can be used for the prediction of the property of compounds with similar molecular structures but out of the initial training set of molecules, maybe not yet synthesized. The model can also be a tool to better understand the property under study.

\section{Results and Discussion}

\section{Development of QSPR models to predict thermal stability}

Thermal stability is one of the most important properties of energetic materials, since the amount of energy released during a decomposition process gives important information about chemical reactivity. Whereas experimental characterization is well defined, notably by calorimetric measurements [44] (temperature and heat of decomposition), until now, only few predictive models have been developed on these properties related to thermal stability.

For instance, Figueiredo [45] and Yu [46] used QSPR type methods for the prediction of specific thermal decomposition properties of chromophores and polymers respectively. Kroon [47] used DFT calculations to estimate the decomposition temperature of some ionic liquids from the activation energies of the most likely thermal degradation reaction. Concerning the thermal stability of potentially explosive compounds, Grewer [48] demonstrated the influence of functional groups on decomposition temperatures $\left(T_{\text {onset }}\right)$. More recently, correlations were highlighted between this property and weak bond dissociation energies for nitroalkanes, nitramines and nitric esters $[49,50]$. But, to our knowledge, Saraf [8] proposed the first QSPR type model considering nitroaromatic compounds with a low correlation of 0.6 :

$$
T_{\text {onset }}\left({ }^{\circ} \mathrm{C}\right)=827.0-1036 \mathrm{HPC}-4.43 \mathrm{Sr}-5.07 \mathrm{DM}
$$

where $H P C$ is the highest positive charge, $S r$ an electron delocalizability index (calculated from molecular orbitals) and $D M$ the dipole moment. In this last paper, decomposition enthalpy $(-\Delta H)$ was also investigated and was estimated to be related to only the number of nitro groups in the molecule $\left(n_{\mathrm{NO} 2}\right)$ with an average absolute error of about $6 \%$ :

$$
-\Delta H(k c a l / m o l)=75 \times n_{N O 2}
$$

Recently, Keshavarz proposed other QSPR type models based on constitutional descriptors for the prediction of the activation energy of thermolysis of nitroaromatics and nitramines leading to a correlation coefficient $\mathrm{R}^{2}=0.87$ [51,52]. 
Our paper presents the first robust models developed to predict the decomposition enthalpy of a set of 22 nitrobenzene derivatives (see table 1). These data have been obtained from differential scanning calorimetry (DSC) measurements from the single reference [53] to ensure their reliability since all data have been determined under the same experimental conditions. Nitroaromatic compounds are characterized by complex decomposition mechanisms [20,21], making the research of a simple indicator of thermal stability more difficult [49]. Then, a particular interest has been dedicated to the use of chemical comprehensive descriptors related to the decomposition of these nitroaromatic compounds.

Table 1. Experimental [53] and predicted decomposition enthalpies (in $\mathrm{kJ} / \mathrm{mol}$ ) from QSPR model (equation 5) of 22 nitrobenzene derivatives.

\begin{tabular}{|c|c|c|c|c|}
\hline Compound & Molecular Structure & Experimental & Predicted & Error (\%) \\
\hline nitrobenzene & & 339 & 319 & -5.9 \\
\hline 1,2-dinitrobenzene & & 518 & 592 & 14.3 \\
\hline 1,3-dinitrobenzene & & 586 & 578 & -1.4 \\
\hline 1,4-dinitrobenzene & & 622 & 592 & -4.8 \\
\hline 2-nitrotoluene & & 329 & 352 & 7.0 \\
\hline 3-nitrotoluene & & 284 & 315 & 10.9 \\
\hline 4-nitrotoluene & & 318 & 313 & -1.6 \\
\hline 2,6-dinitrotoluene & & 576 & 606 & 5.2 \\
\hline 3,4-dinitrotoluene & & 666 & 607 & -8.9 \\
\hline 2,4-dinitrotoluene & & 596 & 606 & 1.7 \\
\hline
\end{tabular}


Table 1. (continued)

\begin{tabular}{|c|c|c|c|c|}
\hline Compound & Molecular structure & Experimental & Predicted & Error (\%) \\
\hline 2-nitroaniline & & 307 & 298 & -2.9 \\
\hline 3-nitroaniline & & 314 & 309 & -1.6 \\
\hline 4-nitroaniline & & 279 & 293 & 5.0 \\
\hline 2-nitrobenzoic acid & & 297 & 317 & 6.7 \\
\hline 3-nitrobenzoic acid & & 298 & 312 & 4.7 \\
\hline 4-nitrobenzoic acid & & 304 & 267 & -12.2 \\
\hline 2-nitrophenol & & 345 & 334 & -3.2 \\
\hline 3-nitrophenol & & 316 & 324 & 2.5 \\
\hline 4-nitrophenol & & 300 & 314 & 4.7 \\
\hline 1-chloro-4-nitrobenzene & & 360 & 317 & -11.9 \\
\hline 2,4-dinitrophenol & & 662 & 657 & -0.8 \\
\hline 2,4,6-trinitrophenol & & 1173 & 1167 & -0.5 \\
\hline
\end{tabular}

In our previous work [54], a set of selected descriptors directly obtained from the quantum chemical calculations at DFT level was calculated. Some of them are related to the nitro group: $\mathrm{C}-\mathrm{NO}_{2}$ distance $\left(d_{C N}\right), \mathrm{C}-\mathrm{NO}_{2}$ dissociation energy $\left(E_{\text {diss }}\right)$, electrostatic potential at the middle of $\mathrm{C}-\mathrm{NO}_{2}$ bond $\left(V_{\text {mid }}\right)$ and nitro charge $\left(Q_{\mathrm{NO} 2}\right)$. The others characterize the properties of the whole molecule: 
dipole moment $(D M)$, mean polarizability $(\alpha)$, atomization energy $\left(E_{\text {atom }}\right)$, ionization potential (IP), electron affinity (EA), electronegativity $(\chi)$, chemical hardness $(\eta)$ and electrophilicity index $(\omega)$.

Moreover, the more empirical molecular weight $(M w)$ and oxygen balance $(O B)$ have also been integrated into the analysis. A first significantly correlated model $\left(\mathrm{R}^{2}=0.91\right)$ has been obtained from this set of 14 selected descriptors. It consisted in the following six-parameter equation [54]:

$$
\begin{gathered}
-\Delta H=33854 \eta+40050 \omega-1030.3 \alpha-33785 I P+25.1 D M-14.0 E_{d i s s}+973.2 \\
R^{2}=0.91, \quad R_{c v}^{2}=0.84
\end{gathered}
$$

This first model presents the interesting behavior to distinguish the molecules among their number of nitro groups and associates chemical comprehensive descriptors like the dissociation energy, already considered in the prediction of the decomposition temperature of nitro compounds [49].

It has to be noted that significant correlations have already been observed for descriptors arising from the so-called conceptual density functional theory (i.e. IP, EA, $\chi, \eta, \omega)$ [55]. Contrary to classical constitutional descriptors (for instance, the classical oxygen balance [56]), they are developed to characterize molecular reactivity within the framework of DFT. Moreover, they present great interest in QSPR models to predict the properties of chemicals because they are able to distinguish isomers, their values being different from one isomer to another.

In order to improve the reliability of the models, a more extended set of descriptors calculated from CodessaPro software have been investigated. This software allows one to include notably constitutional descriptors commonly used for the prediction of various properties of energetic materials, as done by Keshavarz for instance [23-26,51,52,57].

Until now in our study, the descriptors have been obtained from DFT calculated structures but CodessaPro can also compute descriptors from structures calculated at the semi-empirical AM1 level, less computer time consuming than DFT. This is the case for Katritzky's models [39-42]. So, descriptors were computed from molecular structures calculated at both levels to confirm the pertinence of using DFT in this study [58].

Only a slight decrease in correlation coefficients was observed when using DFT or AM1 (about 0.02 in $\mathrm{R}^{2}$ ). Nevertheless, the descriptors integrated in each model are quite different upon the calculation level. In particular, the accuracy of the AM1 model was related to the good correlation of a particular topological descriptor (Wiener index) with the experimental decomposition enthalpy. In fact, AM1 models are mainly constructed on this descriptor which characterizes the degree of substitution on the aromatic ring. This descriptor does not need any advanced calculation level since it is based on the "skeleton" structure of the molecule, and is the same from semi empirical and DFT calculations.

Finally, the DFT based model has been preferred in this study since it demonstrated the advantage to include molecular reactivity properties, in particular quantum calculated descriptors for which a semi empirical level does not ensure accuracy whereas DFT does. This last model, which will be described in the following, was more related to the chemical phenomena involved during the decomposition. 
In this analysis (based on DFT calculated structures), the BMLR analysis was used to select significant descriptors to build multilinear QSPR models. The success to develop QSPR models from the BMLR procedure can be linked to the choice of the best compromise between the number of descriptors in the models and their corresponding correlation coefficient $\mathrm{R}^{2}$ values. As described by Katritzky [40] and illustrated in figure 2, a breaking point is observed in the increasing of $\mathrm{R}^{2}$ with the number of descriptors, among the equations built during the BMLR analysis.

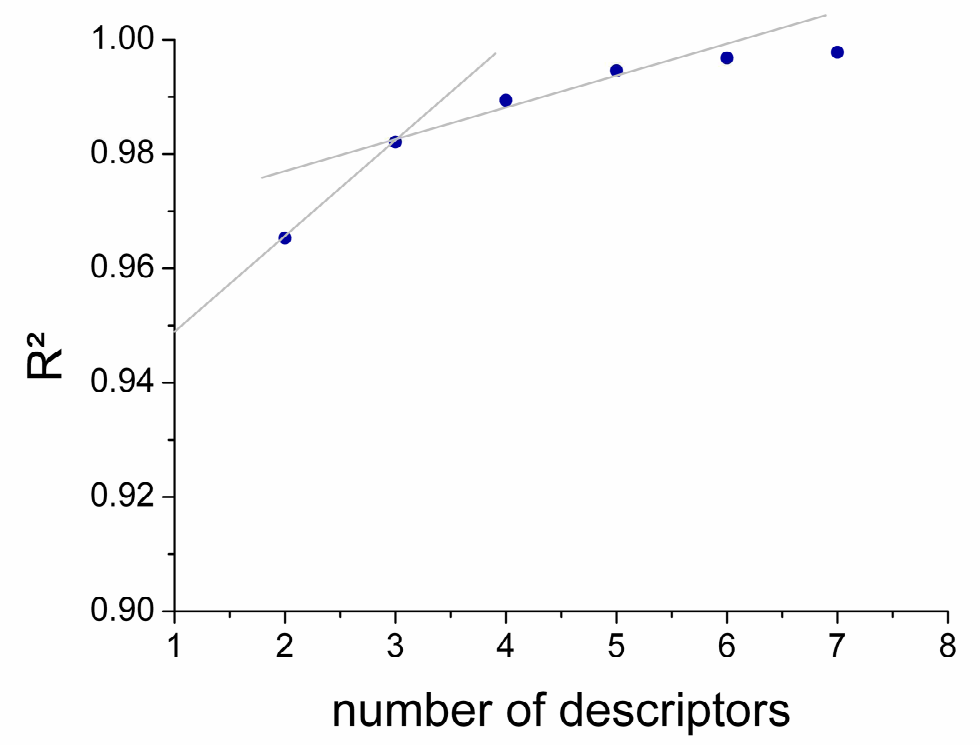

Figure 2. Defining of the optimum number of descriptors based on a "breaking point" rule.

Consequently, the model corresponding to the breaking point considered in our study is the threeparameter model:

$$
\begin{gathered}
-\Delta H=401.6 n_{N}+2092.2 B O_{N, a v g}+13287 E_{O, \max }-3148.5 \\
R^{2}=0.98, \quad R_{c v}^{2}=0.97
\end{gathered}
$$

where $n_{N}$ is the number of $\mathrm{N}$ atom, $B O_{N, \text { avg }}$ is the average bond order for $\mathrm{N}$ atom and $E_{O, \max }$ is the maximum electrophilic reactivity index for a $\mathrm{O}$ atom. This last descriptor is a local conceptual DFT descriptor (also called Fukui index) characterizing the relative reactivity of atoms in a molecule.

The interesting thing is that the three selected descriptors are related to thermal stability and thermal decomposition process of nitro compounds as they can characterize the presence of nitro groups, an indicator of explosive properties (as integrated in pre-evaluation in safety regulations [3]), and their ability to dissociate from the aromatic molecules. 
The predicted values (in table 1) demonstrated a strong correlation with experimental data $\left(\mathrm{R}^{2}=0.98\right)$. Moreover, the predicted values discriminated between the number of nitro groups in the molecule, as observed by experimental ones (see figure 3 ).

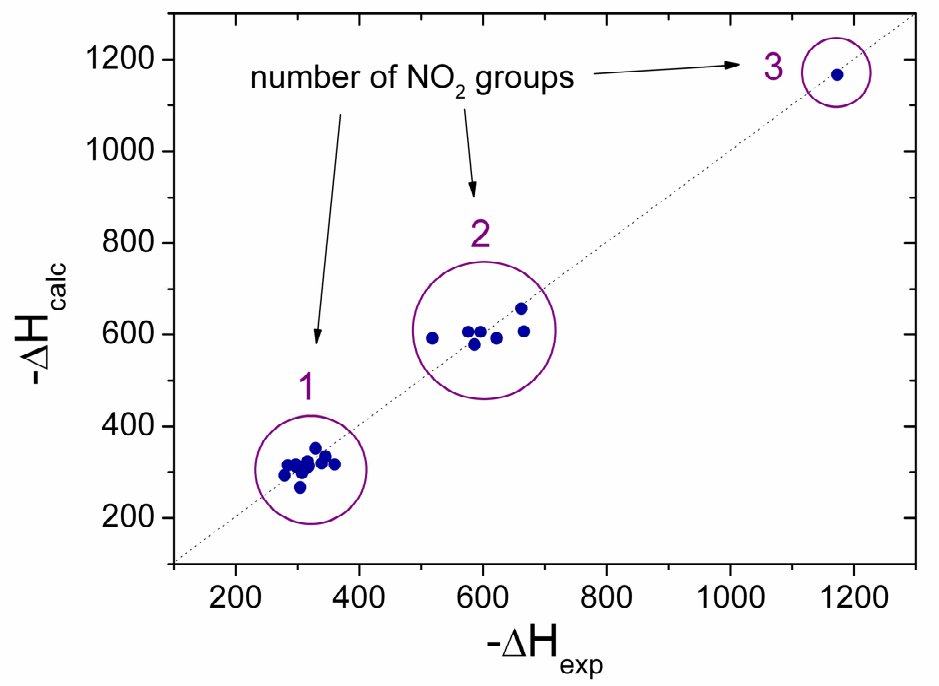

Figure 3. Plot of calculated decomposition enthalpies (in $\mathrm{kJ} / \mathrm{mol}$ ) versus experimental values according to equation (5)

A larger data set, presenting a homogeneous and representative distribution of values and sufficient to have a separated validation set, is of course desirable to validate the reliability of any model, particularly when dedicated to so sensitive properties and compounds. Works in this direction are in progress by extending the data set. Nevertheless, the presented results, summarized in table 2 could predict decomposition enthalpy values for nitroaromatics by using quantum chemical descriptors calculated with DFT and CodessaPro. They are already satisfactory considering the complexity of the studied property and demonstrate the applicability of the method.

Table 2. Comparison between our models developed for the prediction of the decomposition enthalpy

\begin{tabular}{ccccccc}
\hline Descriptors number & Descriptors name & $\mathrm{R}^{2}$ & $\mathrm{R}_{\mathrm{cv}}{ }^{2}$ & molecules & Comments \\
\hline 6 & (Equation 4) & $\eta, \omega, \alpha, I P, D M, E_{\text {diss }}$ & 0.91 & 0.84 & 22 & $\begin{array}{c}\text { BMLR on 14 descriptors; choice of the } \\
\text { equation providing the best } \mathrm{R}^{2} \text { cv }\end{array}$ \\
3 & (Equation 5) & $n_{N}, B O_{N, \text { avg }}, E_{O, \max }$ & 0.98 & 0.97 & 22 & $\begin{array}{c}\text { BML on more than 300 descriptors; } \\
\text { "breaking point" rule }\end{array}$ \\
\hline
\end{tabular}

\section{Development of QSPR models to predict electric spark sensitivity}

Among the different kinds of possible initiation modes causing explosion of energetic materials (heat, impact, shock...), the electric spark sensitivity $\left(E_{E S}\right)$ is not the most investigated through predictive approaches. This can be explained on the one hand because the evaluation of this property is not required in chemical regulatory context and on the other hand because of the complexity of the experimental evaluation in terms of variability of protocols. Indeed, this property is defined as the degree of sensitivity to electrostatic discharge when subjected to a high-voltage discharge from a capacitor and depends strongly on experimental protocol (e.g. configuration of 
electrodes). Moreover, the micro-mechanisms involved during this initiation are not definitely elucidated until now, but could be related to molecular structure, thermal reactivity, sensitivity to mechanic stimuli and parameter of detonation $[59,60]$.

Few studies are reported on this property. Zeman et al. established correlations between the electric spark sensitivity and molecular structure of nitramines [61]. They also demonstrated correlations with other properties like thermal decomposition parameters [59] or detonation velocity [62]. Wang also established correlations between experimental electric spark sensitivity values for nitro arenes compounds and theoretical values of detonation velocity and pressure using DFT methods [63]. He also found that the net charge of the nitro group and the lowest unoccupied molecular orbital have the most importante influence on the electric sensitivity. Nevertheless, to our knowledge, the only QSPR type study about the prediction of this sensitivity is Keshavarz's work for a series of nitroaromatic compounds. This analysis using only constitutional descriptors led to the following four-parameter model with a correlation coefficient $\mathrm{R}^{2}=0.77$ [57]:

$$
E_{E S}=4.60-0.733 n_{C}+0.724 n_{O}+9.16 R_{n H / n O}-5.14 C_{R, O R}
$$

where $n_{C}$ and $n_{O}$ are the number of carbon and oxygen respectively, $R_{n H / n O}$ is the ratio of hydrogen atoms to oxygen ones and $C_{R, O R}$ characterizes the presence of alkyl (-R) or alkoxy (-OR) groups attached to an aromatic ring.

More recently, the same author also proposed a predictive model with significant correlations $\left(\mathrm{R}^{2}=0.94\right)$ [64] dedicated to nitramines by correlating $\mathrm{E}_{\mathrm{ES}}$ with maximum detonation pressures, predicted from constitutional parameters.

In the following presented works, still under study, a more extended set of descriptors was used, integrating descriptors allowing to distinguish isomers (contrary to those considered in Keshavarz's work), in order to find a more efficient model from the same experimental data set. In fact, experimental data are different for one isomer to another and an accurate model is expected to be able to observe these variations.

At this stage, the structures of 26 nitroaromatic molecules including polyaromatic ones (presented in table 3) have been calculated within the DFT framework at PBE0/6-31+G(d,p) level. As for the development of models previously described considering decomposition enthalpy, more than 300 descriptors available in CodessaPro software were computed for each molecule and integrated in a multivariable analysis.

The Best Multi Linear Regression analysis was performed and models up to 13 parameters can be computed. Using the simple "breaking point" rule, the optimum number of descriptors is determined to correspond to the following four-parameter equation (as illustrated in figure 4):

$$
\begin{gathered}
E_{E S}=29.6 n_{\text {sin } g l e}+63.3 N_{C, \text { max }}+168.4 Q_{C, \text { min }}-27.8 V_{C, \text { min }}+99.4 \\
R^{2}=0.90, \quad R_{c v}^{2}=0.78
\end{gathered}
$$


where $n_{\text {single }}$ is the relative number of single bonds and $N_{C, \max }, Q_{C, \min }$ and $V_{C, \min }$ are the maximum nucleophilic reactivity index, the minimum partial charge (calculated from Zefirov's method as implemented in CodessaPro [33]) and the minimum valence for a $\mathrm{C}$ atom, respectively.

Table 3. Experimental [57] and predicted electric spark sensitivity (in J) from QSPR model (equation 7) of 26 nitroaromatic compounds.

\begin{tabular}{|c|c|c|c|c|}
\hline Compound & Molecular Structure & Experimental & Predicted & Error $(\%)$ \\
\hline 2,4,6-trinitrophenol & & 8.98 & 7.57 & -15.7 \\
\hline 1,3,5-trinitrobenzene & & 6.31 & 9.48 & 50.2 \\
\hline 1,8-dinitronaphtalene & & 13.90 & 16.04 & 15.4 \\
\hline 2,4,6-trinitroaniline & & 6.85 & 6.30 & -8.0 \\
\hline 1,5-dinitronaphtalene & & 11.20 & 8.19 & -26.9 \\
\hline 2,6-dimethoxy-3,5-dinitropyridine & & 20.57 & 20.27 & -1.5 \\
\hline 1,4,5,8-tetranitronaphtalene & & 8.26 & 3.87 & -53.1 \\
\hline 2-methoxy-1,3,5-trinitrobenzene & & 28.59 & 27.07 & -5.3 \\
\hline 2,4-dimethyl-1,3,5-trinitrobenzene & & 11.10 & 9.78 & -11.9 \\
\hline (1,3,5-trimethyl)trinitrobenzene & & 8.98 & 8.62 & -4.0 \\
\hline 3,5-dinitropyridine-2,6-diamine & & 12.40 & 10.87 & -12.3 \\
\hline
\end{tabular}


1,3,7,9-tetranitro-10H-phenothiazine -5,5-dioxide

2,4,6-trinitrobenzene-1,3-diol<smiles>O=[N+]([O-])c1cc([N+](=O)[O-])c2c(c1)S(=O)(=O)c1cc([N+](=O)[O-])cc([N+](=O)[O-])c1N2</smiles>

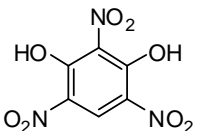

Table 3. (continued)

Compound
3-methyl-2,4,6-trinitrophenol
5,7-dinitro-1-(2,4,6-trinitrophenyl)
-1H-1,2,3-benzotriazole

1,4,5-trinitronaphtalene

1,1'-(1,2-ethendiyl) bis[2,4,6-trinitrobenzene]

1,3,5-trinitro-2-(2,4,6-trinitrobenzyl) benzene

2-chloro-1,3,5-trinitrobenzene

N,N-bis(2,4,6-trinitrophenyl)amine

2,4,6-trinitrobenzene-1,3-diamine

(1,3,5-triamino)trinitrobenzene

2,2'4,4',6,6'-hexanitro-1,1'-biphenyl

1,3,7,9-tetranitro-10H-phenoxazine

\section{Molecular structure}

Experimental

Predicted

Error (\%)

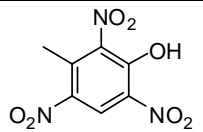

56.8<smiles>O=[N+]([O-])c1cc([N+](=O)[O-])c(-n2nnc3cc([N+](=O)[O-])cc([N+](=O)[O-])c32)c([N+](=O)[O-])c1</smiles>

6.50<smiles>O=[N+]([O-])c1ccc([N+](=O)[O-])c2c([N+](=O)[O-])cccc12</smiles>

10.97

9.46

$-13.8$<smiles>O=[N+]([O-])c1cc([N+](=O)[O-])c(/C=C/c2c([N+](=O)[O-])cc([N+](=O)[O-])cc2[N+](=O)[O-])c([N+](=O)[O-])c1</smiles>

6.60<smiles>O=[N+]([O-])c1cc([N+](=O)[O-])c(Cc2c([N+](=O)[O-])cc([N+](=O)[O-])cc2[N+](=O)[O-])c([N+](=O)[O-])c1</smiles>

4.10

4.53

10.5<smiles>O=[N+]([O-])c1cc([N+](=O)[O-])c(Cl)c([N+](=O)[O-])c1</smiles>

6.71 5.90<smiles>O=[N+]([O-])c1cc([N+](=O)[O-])c(Nc2c([N+](=O)[O-])cc([N+](=O)[O-])cc2[N+](=O)[O-])c([N+](=O)[O-])c1</smiles>

5.02

6.70

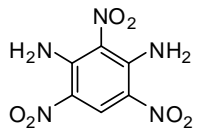

10.97

12.96

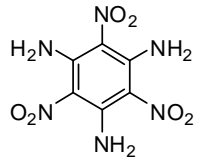

17.75

17.82

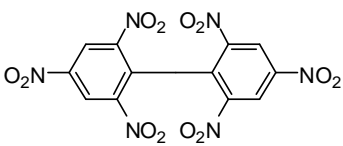<smiles>O=[N+]([O-])c1cc2c(c([N+](=O)[O-])c1)Nc1c(cc([N+](=O)[O-])cc1[N+](=O)[O-])O2</smiles> 
2-methyl-1,3,5-trinitro-

4-[(2,4,6-trinitrophenyl)thio]benzene

2,4,6-trinitrotoluene
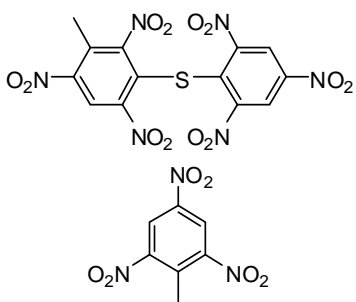

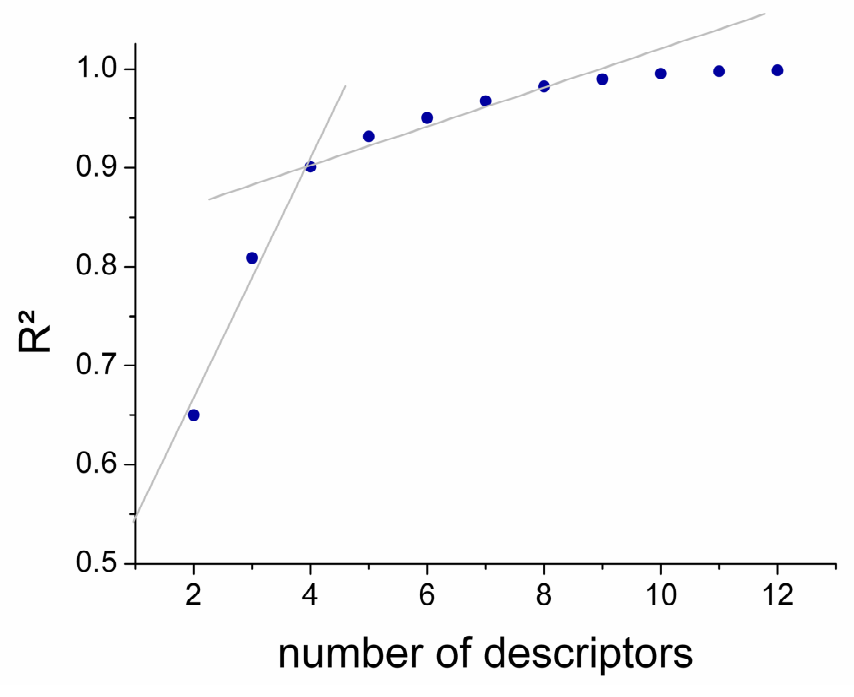

Figure 4. Defining of the optimum number of descriptors based on a "breaking point" rule.

In this model, we can assume that the three last descriptors of the model are addressing the carbon involved in the $\mathrm{C}-\mathrm{NO}_{2}$ bond that is the most liable to break. Since the loss of this $\mathrm{NO}_{2}$ group is commonly considered as the rate-limiting step of decomposition of nitroaromatic compounds, the selection of these descriptors is chemically understandable and pertinent to predict correctly the electric spark sensitivity, an initiation mode of the explosive decomposition.

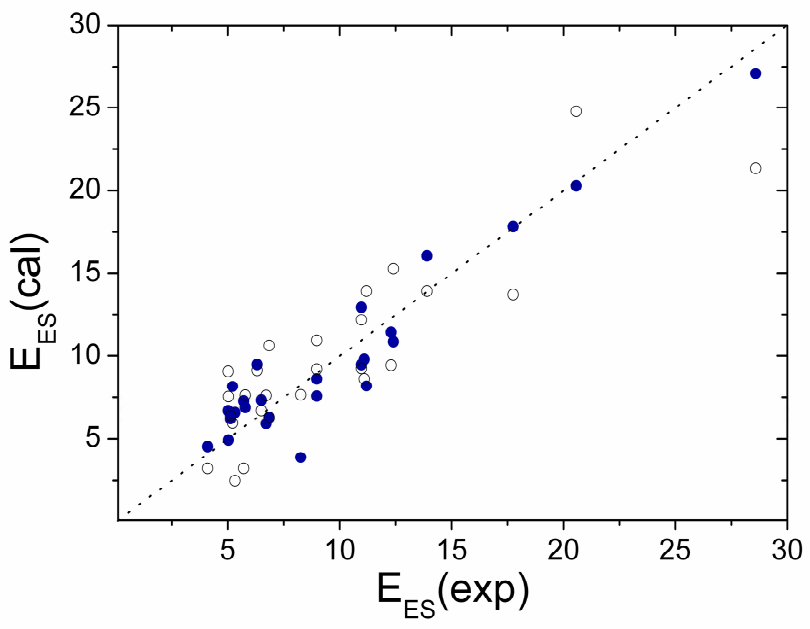


Figure 5. Plot of calculated electric spark sensitivity (in $\mathrm{J}$ ) versus experimental values according to equation 7 (in blue plain circles) and Keshavarz's model [57] (in wide circles).

Investigation about this property is still in progress, to analyze the whole available data set (model keshavarz) and to investigate all the descriptors used for thermal stability (e.g. conceptual DFT descriptors, bond dissociation energy). But this first model already presented an improvement in predictivity from Keshavarz's model $\left(\mathrm{R}^{2}=0.90\right.$ vs. 0.77 , see figure 5$)$.

\section{Conclusion}

Two physico-chemical properties of substances related to the explosibility property of nitroaromatic compounds have been investigated in Quantitative Structure-Property Relationship (QSPR) studies: decomposition enthalpy and electric spark sensitivity. Quantum chemical calculations have been performed to compute the molecular structures of the studied compounds from which molecular scale descriptors were computed. Different kinds of descriptors were investigated: constitutional, topologic, geometric, electronic and quantum chemical.

If the obtained models need consolidation notably in terms of validation using extended data sets, they already upgraded the existing models up to $\mathrm{R}^{2}=0.98$ and 0.90 , for the prediction of decomposition enthalpy and the electric spark sensitivity respectively. Moreover, they integrate descriptors related to the $\mathrm{C}-\mathrm{NO}_{2}$ bond and represent the decomposition sites.

Once strongly validated models are obtained, they will be integrated in a global tool for the management of chemical explosive hazards. Its development is in the line of the search of new methods (required by REACH), not replacing but complementary to experimental tests, able to provide a first evaluation of hazards and to guide to further experimental investigation if necessary.

\section{References}

[1] Regulation (EC) $N^{\circ}$ 1907/2006 of the European Parliament and of the Council of 18 December 2006 concerning the Registration, Evaluation, Authorisation and Restriction of Chemicals (REACH). OJ L 396, 30.12.2006.

[2] United Nations, Globally Harmonized System of Classification and Labelling of Chemicals (GHS), Second revised edition, Geneva - New York, 2007.

[3] United Nations, Recommendations on the Transport of Dangerous Goods: Manual of Tests and Criteria, Fifth revised edition, Geneva - New York, 2009.

[4] E. S. Shanley and G. A. Melhem, A review of ASTM CHETAH 7.0 hazard evaluation criteria, $J$. Loss. Prev. Process Ind., 8 (1995) 261-264.

[5] S. W. Benson, Thermochemical kinetics, Wiley, New York, 1976.

[6] W. C. Lothrop and G. R. Handrick, The Relationship between Performance and Constitution of Pure Organic Explosive Compounds, Chem. Rev., 44 (1949) 419-445.

[7] G. A. Melhem and E. S. Shanley, On the estimation of hazard potential for chemical substances, Process Saf. Prog., 15 (1996) 168-172.

[8] S. R. Saraf, W. J. Rogers and M. S. Mannan, Prediction of reactive hazards based on molecular structure, J. Hazard. Mater., 98 (2003) 15-29. 
[9] C. D. Selassie, R. Garg, S. Kapur, A. Kurup, R. P. Verma, S. B. Mekapati and C. Hansch, Comparative QSAR and the Radical Toxicity of Various Functional Groups, Chem. Rev., 102 (2002) 2585-2606.

[10] S. P. Bradbury, Quantitative structure-activity relationships and ecological risk assessment: an overview of predictive aquatic toxicology research, Toxicol. Lett., 79 (1995) 229-237.

[11] H. Gao, J. A. Katzenellenbogen, R. Garg and C. Hansch, Comparative QSAR Analysis of Estrogen Receptor Ligands, Chem. Rev., 99 (1999) 723-744.

[12] D. A. Winkler, The role of quantitative structure - activity relationships (QSAR) in biomolecular discovery, Brief. Bioinf., 3 (2002) 73-86.

[13] M. Grover, B. Singh, M. Bakshi and S. Singh, Quantitative structure-property relationships in pharmaceutical research - Part 1, Pharm. Sci. Tech. Today, 3 (2000) 28-35.

[14] M. Grover, B. Singh, M. Bakshi and S. Singh, Quantitative structure-property relationships in pharmaceutical research - Part 2, Pharm. Sci. Tech. Today, 3 (2000) 50-57.

[15] A. R. Katritzky, V. S. Lobanov and M. Karelson, QSPR: the Correlation and Quantitative Prediction of Chemical and Physical-Properties from Structure, Chem. Soc. Rev., 24 (1995) 279287.

[16] A. R. Katritzky, M. Karelson and V. S. Lobanov, QSPR as a means of predicting and understanding chemical and physical properties in terms of structure, Pure Appl. Chem., 69 (1997) 245-248.

[17] J. Taskinen and J. Yliruusi, Prediction of physicochemical properties based on neural network modelling, Adv. Drug Deliv. Rev., 55 (2003) 1163-1183.

[18] E. E. Bolton, Y. Wang, P. A. Thiessen and S. H. Bryant, "PubChem: Integrated Platform of Small Molecules and Biological Activities", In Annual Reports in Computational Chemistry, Elsevier, Amsterdam (2008) pp. 217-241.

[19] PubChem, http://pubchem.ncbi.nlm.nih.gov.

[20] G. Fayet, L. Joubert, P. Rotureau and C. Adamo, Theoretical Study of the Decomposition Reactions in Substituted Nitrobenzenes, J. Phys. Chem. A, 112 (2008) 4054-4059.

[21] T. B. Brill and K. J. James, Kinetics and mechanisms of thermal decomposition of nitroaromatic explosives, Chem. Rev., 93 (1993) 2667-2692.

[22] G. Fayet, L. Joubert, P. Rotureau and C. Adamo, A theoretical study of the decomposition mechanisms on substituted ortho-nitrotoluenes, J. Phys. Chem. A, 113 (2009) 13621-13627.

[23] M. H. Keshavarz and H. R. Pouretedal, Simple empirical method for prediction of impact sensitivity of selected class of explosives, J. Hazard. Mater., 124 (2005) 27-33.

[24] M. H. Keshavarz and M. Jaafari, Investigation of the Various Structure Parameters for Predicting Impact Sensitivity of Energetic Molecules via Artificial Neural Network, Propel. Explos. Pyrotechn., 31 (2006) 216-225.

[25] M. H. Keshavarz, H. R. Pouretedal and A. Semnani, Novel correlation for predicting impact sensitivity of nitroheterocyclic energetic molecules, J. Hazard. Mater., 141 (2007) 803-807.

[26] M. H. Keshavarz, Prediction of impact sensitivity of nitroaliphatic, nitroaliphatic containing other functional groups and nitrate explosives, J. Hazard. Mater., 148 (2007) 648-652.

[27] M. J. Kamlet, The Relationship of Impact Sensitivity with Structure of Organic High Explosives. I. Polynitroaliphatic Explosives, Sixth Symposium (International) on Detonation, Coronads, CA, 1976, p. 69-72.

[28] M. J. Kamlet and H. G. Adolph, The relationship of Impact Sensitivity with Structure of Organic High Explosives. II. Polynitroaromatic explosives, Propel. Explos., 4 (1979) 30-34. 
[29] B. M. Rice and J. J. Hare, A Quantum Mechanical Investigation of the Relation between Impact Sensitivity and the Charge Distribution in Energetic Molecules, J. Phys. Chem. A, 106 (2002) 1770-1783.

[30] B. M. Rice, S. Sahu and F. J. Owens, Density functional calculations of bond dissociation energies for $\mathrm{NO}_{2}$ scission in some nitroaromatic molecules, J. Mol. Struct. (THEOCHEM), 583 (2002) 69-72.

[31] J. Gasteiger and J. Zupan, Neural Networks in Chemistry, Angew. Chem. Int. Ed. Engl., 32 (1993) 503-527.

[32] R. Leardi, Genetic algorithms in chemometrics and chemistry: a review, J. Chemometr., 15 (2001) 559-569.

[33] M. Karelson, Molecular Descriptors in QSAR/QSPR, Wiley, New York, 2000.

[34] M. Karelson, V. S. Lobanov and A. R. Katritzky, Quantum-Chemical Descriptors in QSAR/QSPR Studies, Chem. Rev., 96 (1996) 1027-1044.

[35] C. Adamo and V. Barone, Toward reliable density functional methods without adjustable parameters: The PBE0 model, J. Chem. Phys., 110 (1999) 6158-6170.

[36] M. J. Frisch, G. W. Trucks, H. B. Schlegel, G. E. Scuseria, M. A. Robb, J. R. Cheeseman, J. A. Montgomery, Jr., T. Vreven, K. N. Kudin, J. C. Burant, J. M. Millam, S. S. Iyengar, J. Tomasi, V. Barone, B. Mennucci, M. Cossi, G. Scalmani, N. Rega, G. A. Petersson, H. Nakatsuji, M. Hada, M. Ehara, K. Toyota, R. Fukuda, J. Hasegawa, M. Ishida, T. Nakajima, Y. Honda, O. Kitao, H. Nakai, M. Klene, X. Li, J. E. Knox, H. P. Hratchian, J. B. Cross, V. Bakken, C. Adamo, J. Jaramillo, R. Gomperts, R. E. Stratmann, O. Yazyev, A. J. Austin, R. Cammi, C. Pomelli, J. W. Ochterski, P. Y. Ayala, K. Morokuma, G. A. Voth, P. Salvador, J. J. Dannenberg, V. G. Zakrzewski, S. Dapprich, A. D. Daniels, M. C. Strain, O. Farkas, D. K. Malick, A. D. Rabuck, K. Raghavachari, J. B. Foresman, J. V. Ortiz, Q. Cui, A. G. Baboul, S. Clifford, J. Cioslowski, B. B. Stefanov, G. Liu, A. Liashenko, P. Piskorz, I. Komaromi, R. L. Martin, D. J. Fox, T. Keith, M. A. Al-Laham, C. Y. Peng, A. Nanayakkara, M. Challacombe, P. M. W. Gill, B. Johnson, W. Chen, M. W. Wong, C. Gonzalez and J. A. Pople, Gaussian03. Gaussian Inc., Wallington CT, 2004.

[37] M. J. S. Dewar, E. G. Zoebisch, E. F. Healy and J. J. P. Stewart, Development and use of quantum mechanical molecular models. 76. AM1: a new general purpose quantum mechanical molecular model, J. Am. Chem. Soc., 107 (1985) 3902-3909.

[38] Hyperchem 7.0. Hypercube Inc., Gainesville 2002.

[39] A. R. Katritzky, R. Petrukhin, R. Jain and M. Karelson, QSPR Analysis of Flash Points, J. Chem. Inf. Comput. Sci., 41 (2001) 1521-1530.

[40] A. R. Katritzky, I. B. Stoyanova-Slavova, D. A. Dobchev and M. Karelson, QSPR modeling of flash points: An update, J. Mol. Graph. Model., 26 (2007) 529-536.

[41] A. R. Katritzky, L. Pacureanu, D. Dobchev and M. Karelson, QSPR Study of Critical Micelle Concentration of Anionic Surfactants Using Computational Molecular Descriptors, J. Chem. Inf. Model., 47 (2007) 782-793.

[42] A. R. Katritzky, S. H. Slavov, D. A. Dobchev and M. Karelson, Rapid QSPR model development technique for prediction of vapor pressure of organic compounds, Comput. Chem. Eng., 31 (2007) 1123-1130.

[43] CodessaPro. University of Florida, 2002.

[44] T. Grewer, Thermal Hazards of Chemical Reactions, Elsevier, Amsterdam, 1994.

[45] L. J. O. Figueiredo and F. M. S. Garrido, Chemometric analysis of nonlinear optical chromophores structure and thermal stability, J. Mol. Struct. (THEOCHEM), 539 (2001) 75-81. 
[46] X. Yu, Z. Xie, B. Yi, X. Wang and F. Liu, Prediction of the thermal decomposition property of polymers using quantum chemical descriptors, Eur. Polym. J., 43 (2007) 818-823.

[47] M. C. Kroon, W. Buijs, C. J. Peters and G.-J. Witkamp, Quantum chemical aided prediction of the thermal decomposition mechanisms and temperatures of ionic liquids, Thermochim. Acta, 465 (2007) 40-47.

[48] T. Grewer, The influence of chemical structure on exothermic decomposition, Thermochim. Acta, 187 (1991) 133-149.

[49] E. Theerlynck, D. Mathieu and P. Simonetti, Towards improved models to rationalize and estimate the decomposition temperatures of nitroalkanes, nitramines and nitric esters, Thermochim. Acta, 426 (2005) 123-129.

[50] S. R. Saraf, W. J. Rogers and M. S. Mannan, Application of Transition State Theory for Thermal Stability Prediction, Ind. Eng. Chem. Res., 42 (2003) 1341-1346.

[51] M. H. Keshavarz, Simple method for prediction of activation energies of the thermal decomposition of nitramines, J. Hazard. Mater., 162 (2009) 1557-1562.

[52] M. H. Keshavarz, H. R. Pouretedal, A. Shokrolahi, A. Zali and A. Semnani, Predicting activation energy of thermolysis of polynitro arenes through molecular structure, J. Hazard. Mater., 160 (2008) 142-147.

[53] Y. S. Duh, C. Lee, C. C. Hsu, D. R. Hwang and C. S. Kao, Chemical incompatibility of nitrocompounds, J. Hazard. Mater., 53 (1997) 183-194.

[54] G. Fayet, P. Rotureau, L. Joubert and C. Adamo, On the prediction of thermal stability of nitroaromatic compounds using quantum chemical calculations, J. Hazard. Mater., 171 (2009) 845-850.

[55] G. Fayet, L. Joubert, P. Rotureau and C. Adamo, On the use of descriptors arising from the conceptual density functional theory for the prediction of chemicals explosibility, Chem. Phys. Lett., 467 (2009) 407-411.

[56] E. S. Shanley and G. A. Melhem, The oxygen balance criterion for thermal hazards assessment, Process Saf. Prog., 14 (1995) 29-31.

[57] M. H. Keshavarz, Theoretical prediction of electric spark sensitivity of nitroaromatic energetic compounds based on molecular structure, J. Hazard. Mater., 153 (2008) 201-206.

[58] G. Fayet, P. Rotureau, L. Joubert and C. Adamo, QSPR Modeling of Thermal Stability of Nitroaromatic Compounds: DFT vs. AM1 Calculated Descriptors, J. Mol. Model., In Press.

[59] S. Zeman, "A study of chemical micro-mechanisms of initiation of organic polynitro compounds", In P. PolitzerandJ. S. Murray (Eds.), Energetic Materials. Part 2: Detonation, Combustion, Elsevier, Amsterdam (2003) pp. 25-52.

[60] F. Hosoya, K. Shiino and K. Itabashi, Electric-spark sensitivity of Heat-Resistant Polynitroaromatic Compounds, Propel. Explos. Pyrotechn., 16 (1991) 119-122.

[61] S. Zeman, V. Pelikan and J. Majzlik, Electric Spark Sensitivity of Nitramines. Part I. Aspects of Molecular Structure, Centr. Eur. J. Energ. Mat., 3 (2006) 27-44.

[62] V. Zeman, J. Koci and S. Zeman, Electric Spark Sensitivity of Polynitro Compounds: Part III. A Correlation with Detonation Velocities of some Nitramines, HanNeng CaiLiao, 7 (1999) 172175.

[63] G. Wang, H. Xiao, X. Ju and X. Gong, Calculation of detonation velocity, pressure and electric spark sensitivity of nitro arenas based on quantum chemistry, Propel. Explos. Pyrotechn., 31 (2006) 361-368.

[64] M. H. Keshavarz, H. R. Pouretedal and A. Semnani, Reliable prediction of electric spark sensitivity of nitramines: A general correlation with detonation pressure, J. Hazard. Mater., 167 (2009) 461-466. 
